\title{
Monoclonal antibodies - a revolutionary therapy in multiple sclerosis
}

\author{
Carmen Adella Sirbu ${ }^{1,2}$, Magdalena Budisteanu, ${ }^{1,3,4}$, Cristian Falup-Pecurariu, \\ ${ }^{1}$ Titu Maiorescu University, Bucharest, Romania \\ ${ }^{2}$ Dr. Carol Davila' Central Military Emergency University Hospital, Clinic of Neurology, Bucharest, Romania \\ ${ }^{3}$ Prof. Dr. Alex Obregia' Clinical Hospital of Psychiatry, Psychiatry Research Laboratory, Bucharest, Romania \\ "Victor Babes' National Institute of Pathology, Bucharest, Romania \\ ${ }^{5}$ Faculty of Medicine, Transylvania University of Brașov, Brașov, Romania \\ ${ }^{6}$ Department of Neurology, County Emergency Clinic Hospital, Brașov, Romania
}

\begin{abstract}
Introduction. Multiple sclerosis (MS) has an increasing incidence and affects a young segment of the population, having a major impact on patients and consequently on society. The multifactorial aetiology and pathogenesis of this disease are incompletely known at present, but autoimmune aggression has a documented mechanism.

State of the art. Since the 1990s, immunomodulatory drugs of high efficacy and a good safety profile have been launched. But the concept of NEDA (No Evidence of Disease Activity) remains the target to achieve. Thus, the new revolutionary class of monoclonal antibodies (moAbs) used in multiple medical fields, from this perspective represents a challenge even for multiple sclerosis, including the primary progressive form, for which there has been no treatment until recently.

Clinical implications. In this article, we will review monoclonal antibodies' use for MS, presenting their advantages and disadvantages, based on data accumulated since 2004 when the first monoclonal antibody was approved for active forms of the disease.

Future directions. There is still a need for personalised medicines, with a specific target, which should have fewer adverse effects and drug interactions.

Key words: multiple sclerosis, monoclonal antibodies, safety, natalizumab, alemtuzumab, ocrelizumab

(Neurol Neurochir Pol 2020; 54 (1):21-27)
\end{abstract}

\section{Introduction}

Multiple sclerosis (MS) is characterised by inflammation, focal demyelination at multiple locations and by a process of axonal degeneration in a person with genetic susceptibility to the disease. It affects young people, with more women than men, a ratio that is growing from $1.4 / 1$ to $2.3 / 1$ [1].

The rational use of MS therapy, following current guidelines, patient particularities, and clinical experience, is an important task that involves great responsibilities from all team members (patient, physician, and government structures). The physician's role is even more difficult, given the wide range of drugs in use today to which biosimilars/biogenerics are being added.

\section{State of the art}

The first drugs developed to treat MS were from the interferon class, and the first Food and Drug Administration (FDA) approval was granted in 1993 for Interferon beta $1 \mathrm{~b}$ (IFNB-1b) [2]. Three years later, another drug - glatiramer acetate - was released onto the market. These drugs, known as disease-modifying therapies (DMTs), have shown a good longterm safety profile but suboptimal efficacy $[3,4]$. A substantial 
percentage of the treated patients withdraw from treatment or change it because there is no real benefit [5]. Another problem, that has for decades decreased patient adherence to treatment, is its administration method - by injection [6].

Researchers continue to investigate developing drugs that can stop the evolution of the disease (NEDA - no evidence of disease activity), with low costs, good safety profile and convenient administration, to increase patient adherence to treatment. Interferons and copolymers are useful because secondgeneration drugs, although more effective, come with a lower safety profile and higher costs. The pathogenic mechanism of the disease has been partially identified. The initiation of the autoimmune process is done as we know it in the periphery. For MS pathogenicity, B cells play an important role, modulating antigen-presenting cells and T cell production and influencing the innate immunity [7]. Some antigens can activate cells of the immune system in individuals with a genetic predisposition under the influence of environmental factors. These activated immune cells synthesise cytokines (interleukins IL 6, 17, 23, interferon-gamma, and TNF alpha, among others) with the inflammatory role as well as activate Th lymphocytes towards other pro-inflammatory lymphocytes. These cytokines activate the adhesion molecules from the capillary wall (VCAM, VLA 4, E selectin, ICAM), altering the blood-brain barrier (BBB) permeability. Endothelial cells play an important role in inflammation. For example, EndoMT is a novel process where endothelial cells return to mesenchymal cells and lose their ability to maintain brain homeostasis [8]. Through this autoimmune cascade, inflammation, demyelination, and axonal damage appear from the earliest stages of the disease $[9,10]$. These mediators of inflammation have been identified in MS lesions, although it was for a long time considered that only self-reactive CD4 cells had this role [10]. The involvement of the humoral immune response, which is more documented nowadays, has turned antibodies against $B$ cells into new therapeutic targets $[11,12]$. The integrity of the BBB is essential for the passage of drugs to the nervous system. Because of its high molecular weight, smaller amounts of moAb pass into the brain. Only $15 \%$ of 51 anti-cancer systemic drugs pass over an intact BBB. MoAbs can be labelled with radioactive isotopes like $89 \mathrm{Zr}$-antibody-PET. In this regard, PET imaging is in use in several clinical studies as a potential imaging biomarker for drug BBB penetration $[13,14]$.

MoAbs are antibodies from identical immune cells, which are obtained from a stem cell by cloning. They are in a continuous process of development, as were interferons in the glorious 1970s when they were considered to be remedies for many diseases [15].

We can say that both classes belong to biopharmaceuticals that determine, due to their immunogenicity, the appearance of anti-drug antibodies (ADAs), with unpleasant effects for pharmacokinetics and therefore for efficacy [16], hence drawing another parallel between interferons and moAbs. This phenomenon was initially described as the first moAb for therapeutic purposes, approved by the FDA in 1992 to prevent the rejection of transplanted organs. Muromonab (the only moAb that does not have the common '-mab' suffix imposed since 2008 in their terminology) targets the CD3 antigen and comes only from mice, with a high degree of immunogenicity. Thus, antibodies against these proteins of murine origin appear with repeated exposure to the drug. Through the development of biotechnologies, this disadvantage has been largely solved as moAb dedicated to MS treatment is over $90 \%$ humanised (natalizumab, alemtuzumab, and ocrelizumab - currently used) or $100 \%$ human (ofatumumab, opicinumab, and secukinumab - in different stages of research) [11].

Studies have revealed that by starting treatment as early as possible and with more active drugs, conversion to progressive disease may be delayed. Brown et al. studied this aspect by analysing transition from a relapsing form to a progressive disease for three categories of patients: those not treated or treated late, those treated with first-line DMTs (GA or IFNB), and those treated with more active drugs such as fingolimod, alemtuzumab, and natalizumab. The results were conclusive. The 1,555 patients were followed up with for at least four years. The conversion rate to the progressive form of MS was lower in those treated with first-generation DMTs (GA and INFs) compared to those with a natural evolution of disease $(12 \%$ vs. 27\%, 5-year absolute risk). Patients initially treated with natalizumab, alemtuzumab, and fingolimod had a progressive conversion rate of $7 \%$ versus $12 \%$, as did those treated with GA or IFNB after an average follow up of 5.8 years. If the escalation of the therapy (from GA and IFNB to natalizumab, alemtuzumab, or fingolimod) was done in the first five years and not later, the risk was $8 \%$ versus $14 \%$ (5-year absolute risk) [17]. Harding et al. demonstrated that the average time of 5-year progression to disability is shorter in patients whose treatment escalation is later than it is in those who are treated aggressively from the beginning (3.14 vs. 6.0, $\mathrm{p}=0.05$ ).

Thus, in the real world, early and aggressive treatment of patients brings benefits compared to delayed treatment or treatment with first-generation DMTs. However, comparative studies are needed to help establish therapeutic strategies [18].

\section{Clinical implications}

The first moAb released onto the market was natalizumab, approved by the FDA in 2004, 12 years after the discovery of target integrin, for recurrent highly active relapsing forms of MS $[19,20]$. Natalizumab has already been used for 15 years in the US and 13 years in Europe. It acts on VLA-4 integrin on leukocytes and myeloid cells and limits their passage through the BBB into the nervous system [21]. It also decreases LT reactivation and $L B$ proliferation [22]. The AFFIRM and SENTINEL studies were sufficient to obtain approval for use (Tab. 1) [23]. The ASCEND Phase III study for patients under natalizumab treatment was negative (without benefits in the progression of secondary progressive multiple sclerosis 
Table 1. Summary of practical aspects of monoclonal antibodies (moAbs) therapies approved for Multiple Sclerosis

\begin{tabular}{|c|c|c|c|}
\hline MoAbs & Natalizumab & Alemtuzumab & Ocrelizumab \\
\hline \multirow[t]{2}{*}{ Approval date } & FDA-2004 & EMA-2013 & FDA-2017 \\
\hline & EMA-2006 & FDA-2014 & EMA-2018 \\
\hline $\begin{array}{l}\text { Mechanism of } \\
\text { action }\end{array}$ & $\begin{array}{l}\text { A humanised recombinant anti- } \\
\text {-VLA-4 integrin antibody }\end{array}$ & $\begin{array}{l}\text { A humanised monoclonal antibody, } \\
\text { which acts selectively on the CD52 } \\
\text { epitope }\end{array}$ & $\begin{array}{l}\text { Humanised recombinant monoclonal antibo- } \\
\text { dy with } C D 20 \text { epitope target }\end{array}$ \\
\hline $\begin{array}{l}\text { Clinical trials } \\
\text { phase III }\end{array}$ & $\begin{array}{l}\text { AFFIRM: Reduction of RRR with } 68 \% \\
(p<0.001) ; 83 \% \text { red. of les. in T2 } \\
(p<0.001), 76 \% \text { of les. in T1 } \\
(p<0.001) ; 92 \% \text { less active les. } \\
(p<0.001) \text { compared to placebo; } \\
\text { progression } 17 \% \text { compared to } 29 \% \\
\text { from placebo ( } p<0.001) \\
\text { SENTINEL: } 55 \% \text { reduction in RRR for } \\
\text { IFNB and natalizumab group com- } \\
\text { pared to placebo ( } p<0.001) ; 83 \% \\
\text { reduction in T2 les. at } 2 \text { years; } 89 \% \\
\text { reduction of T1 enhancing les. at } \\
2 \text { years ( } p<0.001) ; 24 \% \text { reduction } \\
\text { of progression at } 2 \text { years ( } p<0.001 \text { ) }\end{array}$ & $\begin{array}{l}\text { CARE-MS I: } 40 \% \text { vs. } 22 \% \text { relapses ratio } \\
\text { (IFNb1a vs. Alemtuzumab); T2 les. was } \\
58 \% \text { vs. } 48 \% \text { (IFNb-1a vs. Alemtuzu- } \\
\text { mab);T1 enhancing les. } 19 \% \text { versus } 7 \% \\
\text { ( } p<0.0001 \text { ). } \\
\text { CARE-MS II: } \\
51 \% \text { vs. } 35 \% \text { IFNb-1a RRR vs. Alemtu- } \\
\text { zumab; T2 lesion I } 68 \% \text { compared to } \\
46 \% \text { (IFNb-1a vs. Alemtuzumab); T1 } \\
\text { enhancing les. } 23 \% \text { vs. } 9 \%(p<0.0001 \text { ) }\end{array}$ & $\begin{array}{l}\text { OPERA I: Ocrelizumab vs. IFNb1a-reduction of } \\
\text { RRR with } 46 \% \text { ( } p<0.001) ; \text { T2 les. (Ocrelizumab } \\
\text { vs. IFNb1a) } 38.3 \% \text { vs. } 61.3 \% ; \text { T1 enhancing } \\
\text { les. } 8.3 \% \text { vs. } 30.2 \%(\text { Ocrelizumab vs. IFNb1a); } \\
\text { progression } 9.1 \% \text { vs. } 13.6 \% \text { ( } p<0.001) \text {. } \\
\text { OPERA II: Ocrelizumab vs. IFNb1a reduction } \\
\text { of RRR with } 47 \% \text { ( }<<0.001) ; \text { T2 les. } 39.1 \% \text { vs. } \\
62.0 \% \text {; } \\
\text { T1 enhancing les. } 9.8 \% \text { vs. } 36.1 \% \text {; progression } \\
9.1 \% \text { vs.13.6 } \% \text { ( }<0.001) ; \\
\text { ORATORIO: brain-volume loss } 0.9 \% \text { vs. } 1.09 \% \text {, } \\
\text { p=0.02 (Ocrelizumab vs. placebo); patients } \\
\text { with progression (\%) } 32.9 \% \text { vs. } 39.3 \%, p=0.03 \\
\text { (Ocrelizumab vs. placebo) }\end{array}$ \\
\hline Administration & $\begin{array}{l}\text { Injection } 300 \mathrm{mg} / 30 \mathrm{~mL} \text { in a single- } \\
\text {-dose, } 1 \mathrm{monthly} \text {; over } 2 \text { years } \\
\text { treatment is continued after risk } \\
\text { stratification }\end{array}$ & $\begin{array}{l}\text { Cycle I- } 2 \mathrm{mg} / \text { day for } 5 \text { days; Cycle II } \\
-12 \text { mg/day for } 3 \text { days, administered } \\
\text { one year after Cycle I }\end{array}$ & $\begin{array}{l}\text { Injection of } 300 \mathrm{mg} / 10 \mathrm{ml} \text { : the first perfusion } \\
\text { with } 300 \mathrm{mg} \text {, followed after } 2 \text { weeks by the } \\
\text { second perfusion with } 300 \mathrm{mg} \text {. A second dose } \\
\text { of } 600 \mathrm{mg} \text { after } 6 \text { months }\end{array}$ \\
\hline Side effects & $\begin{array}{l}\text { PML, infusion reactions, fatigue, } \\
\text { allergies, infections, gastrointestinal } \\
\text { disorders, neoplasms }\end{array}$ & $\begin{array}{l}\text { Infusion reactions, infections, cardiac } \\
\text { arrhythmias, autoimmune disorders, } \\
\text { myocardial infarctions, stroke, death }\end{array}$ & $\begin{array}{l}\text { Infusion-related reactions, infections, } \\
\text { neoplasms }\end{array}$ \\
\hline Special remarks & $\begin{array}{l}\text { REMS platform enabled - this MoAb } \\
\text { is subject to further monitoring, for } \\
\text { quick identification of new infor- } \\
\text { mation related to safety. Requires } \\
\text { monitoring after discontinuation of } \\
\text { treatment }\end{array}$ & $\begin{array}{l}\text { It requires prophylactic adjuvant } \\
\text { treatment, peri-infusion; } \\
\text { REMS platform enabled. In April } 2019 \\
\text { EMA restricted the use of Lemtrada } \\
\text { until the emergence of new dataRe- } \\
\text { quires monitoring after discontinu- } \\
\text { ation of treatment }\end{array}$ & $\begin{array}{l}\text { It requires prophylactic adjuvant treatment, } \\
\text { peri-infusion. Requires monitoring after } \\
\text { discontinuation of treatment }\end{array}$ \\
\hline
\end{tabular}

Gd - gadolinium; IFNb-1a — interferon beta-1a; MRI — magnetic resonance imaging; PML — progressive multifocal leukoencephalopathy; REMS — Risk Evaluation And Mitigation Strategy; RRR — relapses relative ratio; les. - lesion

- SPMS). These studies, along with those performed for patients with Crohn's disease, also revealed undesirable aspects.

In February 2005, natalizumab was banned because of three deaths due to progressive multifocal leukoencephalopathy (PML) [20]. In 2006, after the plan for stratifying the risk of PML was developed and implemented in the patients treated with natalizumab, it returned onto the market with a special regime for safety assessment. PML is caused by John Cunningham polyomavirus (JCV). The name is that of the first patient identified with this disease [24]. It was first described in patients with immunosuppression. In 2018, the calculated incidence for PML among natalizumab-treated patients was 14.6 per 1,000 individuals [25]. Rituximab, dimethyl fumarate, and fingolimod are associated with a risk of PML [26]. In healthy people, more than $50 \%$ are seropositive for JCV. Studies have uncovered that over the course of a year, the concentration of antibodies fluctuates (seropositive or seronegative) at a rate of $3-10 \%$ for patients treated with natalizumab [27].
JCV penetration into oligodendrocytes coincides with the onset of infection, which in the first 3-6 months (when it is asymptomatic) can be detected only by serial MRI. There are rapidly evolving lesions that have certain characteristics (subcortical, involving ' $\mathrm{u}$ ' fibres, hyperintense DWI and T2 lesions and hypointense T1 lesions) [28].

In 2007, the FDA developed a regularly updated REMS (Risk Evaluation and Mitigation Strategy) platform that helps professionals reduce the risk of PML or detect it swiftly. Given the magnitude of the registered cases, in 2009, 'The PML Consortium' was set up for better management of the situation and new research. Furthermore, it has developed a programme for prescribing natalizumab for patients with MS and Crohn's Disease, known as TOUCH (Tysabri Outreach Unlimited Commitment to Health).

The insufficient exploitation of data from approximately 80,000 MS patients treated with natalizumab worldwide in 2011 , of which only $50 \%$ were in the US, brought great criticism 
from researchers [29]. The EMA established an algorithm for stratifying the risk of PML, dedicated to the professionals who monitor the patients treated with this moAb. This states that the identification of cases of clinically asymptomatic PML by MRI leads to good clinical results and longer survival. Up to June 2016, 667 PML cases were reported from 152,500 patients treated worldwide with natalizumab (an incidence rate of $4.2 / 1,000$ ) with a survival rate of $70-75 \%$ [30]. The birth defects rate for women exposed to natalizumab was 5.05\% versus that of unexposed women, according to data obtained from 350 pregnancies. Other parameters such as abortion rates and baby weights were similar to those of the general population. Exposure to natalizumab in the last trimester has been correlated with haematological abnormalities in the newborn. The drug is found in breast milk, so breastfeeding is not desirable. Interruption of natalizumab before or during pregnancy can trigger severe relapses [31]. In the STRATA study, 3.460 patient-years on natalizumab had a lower annualised relapse rate and stable EDSS score during five years of a survey than did a placebo or other DMTs. The safety profile consists of $16 \%$ serious adverse events, $5 \%$ infusion reactions, $4 \%$ infections, $2 \%$ neoplasms, and 14 PML cases. In the TOP study, conducted on 4.821 patients, the ARR decreased from 1.99 to 0.31 after 12 months and EDSS remained stable (natalizumab vs other DMTs) [32].

Alemtuzumab is another moAb approved for MS therapy. Authorisation for putting it onto the market was granted for the treatment of leukemia in 2001, and withdrawn in 2012 at the request of the manufacturer. Alemtuzumab binds to $\mathrm{CD} 52$, a surface antigen that is present in great numbers in $\mathrm{LT}(\mathrm{CD} 3+)$ and $\mathrm{LB}(\mathrm{CD} 19+)$, and in smaller numbers in natural killer, monocyte and macrophage cells. It acts by cell cytolysis and complement-mediated lysis, producing lymphopenia. B cells re-circulate in about three months, which explains the appearance of humoral-mediated autoimmune diseases during therapy.

T-cells from peripheral blood reappear in significant volumes after 1-1.5 years. This particularity ensures the spaced administration of the drug, thereby improving adherence. On the other hand, long-term suppression of LT causes the effect to not be quickly counteracted in the event of other immune disorders, with the risk of secondary autoimmunity assessed as being $50 \%$ at five years $[33,34]$.

The CARE-MS I and CARE-MS II studies demonstrated beneficial results [11]. Based on these (Tab. 1), alemtuzumab was approved in the treatment portfolio of adults with active disease.

Clinical studies have reported the following as the main side effects: injection-related reactions, autoimmune disorders (thyroiditis, thrombocytopenia, and haemolytic anaemia), nephropathy, infections (herpes, papilloma, listeria), meningoencephalitis, lymphohistiocytosis, and neoplasms, among others. A significant percentage of serious adverse effects (AEs), $8-22 \%$, has been documented in patients treated in phase II and III studies [32]. However, the 5-year extension of CARE-MS studies revealed stability or improvement in disability (69\% and 65\%) with a good safety profile [32].

Less than 200 cases of exposure to alemtuzumab during pregnancy are known. This drug does not cross the placenta, at least not in the first trimester. Breastfeeding is not allowed during treatment. The autoimmunity induced by alemtuzumab, that manifests as thyroiditis in $30-40 \%$ of patients, can induce foetal hypothyroidism [31].

In April 2019, the EMA restricted the use of Lemtrada until new data became available due to the following healthrelated risks: cardiovascular diseases that start in the first days of administration (myocardial infarction, stroke, and arterial dissections), immune-mediated disorders (autoimmune hepatitis and lymphohistiocytosis), and severe neutropenia.

During the re-evaluation period, treatment with Lemtrada is only allowed for adults with a very active form of RRMS or in situations when DMTs cannot be administered. The EMA committee responsible for drug safety issues (the Pharmacovigilance Risk Assessment Committee, PRAC) also recommended updating the information on Lemtrada so that patients and doctors are informed about all aspects of this therapy. The REMS platform, also activated for this moAb (as it is for natalizumab), implies careful monitoring. Pharmacovigilance and stratification of infectious risks require screening for varicella, treponema pallidum, hepatitis $B$, hepatitis $C$, tuberculosis, and HIV infection [25]. In addition to these measures, during the therapy and for four years after the last infusion, blood tests should be monitored monthly, a clinical examination should be performed every three months, and an MRI examination should be conducted every 12 months [35].

Ocrelizumab is another monoclonal antibody. The exact mechanisms of action in MS are not fully understood. It selectively acts on a CD20 epitope, from B lymphocytes, and involves immunomodulation by reducing their number and function for approximately 18 months [36]. The replication capacity of B-lymphocyte is unaffected. Moreover, innate immunity and total $\mathrm{T}$ lymphocyte number are preserved. Being a fully humanised antibody, the benefit/risk ratio is expected to be better than for other humanised or murine moAbs in terms of ADA occurrence.

The results of the three main clinical studies, based on which Ocrevus obtained approvals for use on the market, are summarised in Table 1 . The effects are even more spectacular in light of the fact that absence of disease activity (NEDA) was found in $66.4 \%$ of patients treated with ocrelizumab compared to $24.3 \%$ in the group treated with IFNB-1a. (11) [37]. A 2017 meta-analysis, that included 21,768 participants with RRMS from 33 clinical trials, revealed that ocrelizumab, alemtuzumab, and natalizumab reduced the relapse rate by $70 \%$ compared to interferon, glatiramer acetate, and placebo [38]. For ocrelizumab, injection reactions are more frequent and intense compared to natalizumab and alemtuzumab: allergic reactions of different intensities, dyspnoea, bronchospasm, 
fever, and tachyarrhythmias among others (in clinical trials, they reached $34-40 \%$, although patients were preventively treated with corticosteroids and other risk reduction drugs). Reactivation of hepatitis and the development of neoplasms, especially in the breast, are other challenges. The risk of PML should be taken into consideration, although such cases have not been reported in clinical trials.

This has all led to a risk assessment strategy that considers possible infections, warnings about possible vaccines, and careful monitoring during treatment (clinical and laboratory).

It is not known whether ocrelizumab can affect reproduction or cause foetal injury in humans because there has been no controlled data in pregnancy. But renal, testicular, or bone marrow toxicity, as well as increased perinatal mortality, have been revealed by animal studies. Ocrelizumab is excreted into animal milk. A study of 267 pregnancies with accidental exposure to ocrelizumab did not suggest an increased risk for the foetus [39].

Depending on the mechanism of action of moAbs, therapy may be pulsed, with prolonged effect over time (alemtuzu$\mathrm{mab}$ ), or continued immunosuppression (natalizumab). For ocrelizumab, there is insufficient data to place it in either of these two categories. Pulsed immune reconstitution therapy, also called pulsed immunosuppressive therapy, has several characteristics compared to continued immunosuppression. The first of these is that the effect persists after the cessation of therapy. There is also a higher risk for reactivation of latent infections, a lower risk for PML and malignancy, and an elevated risk of adverse effects in the long term after the cessation of therapy [40].

A recent systematic review revealed that alemtuzumab, ocrelizumab, and natalizumab have better profiles than other drugs, classified as high-efficacy drugs for MS (an advantage in progressing disability and relapse rates). Regarding threemonth disability progression, natalizumab was better than GA and IFNB, and ocrelizumab and alemtuzumab were better than other DMTs. These moAbs have a lower rate for dropout than the other DMTs [41].

Rituximab (RTX) is a mouse chimeric antibody that targets CD20 B cells together with two other moAbs, one fully human (ofatumumab) and one humanised (ocrelizumab). Although they have the same mechanism of action, unlike OCR, RTX does not have approval for use in MS. RTX has been tested in phase II and III clinical studies for RMS and PMS, but the manufacturer stopped producing it. As there was no evidence of its effectiveness and safety, it was not allowed to enter the market. Data from real life and comparative studies with OCR has highlighted many differences. For RTX, there is no evidence of malignancy (it has been used for almost 20 years to treat other diseases), but it has better efficacy and more immunogenicity than OCR. Other studies have compared RTX to fingolimod, GA, and IFNB, revealing a better profile of efficacy and safety. Even the Olympus trial for PPMS demonstrated a reduction of disability compared to placebo.
In this context, RTX is used off label in some countries such as Sweden (40\% of all DMTs) [42, 43].

Daclizumab (DAC) was the first moAb (90\% murine and $10 \%$ human) approved by the FDA in 1997 to prevent renal rejection after a transplant. It works against $\mathrm{CD} 25$ alpha chain (a subunit of the IL-2 receptor of T-cells). DAC was approved in 2016 for once-monthly injection in RMS for adults. The phase II and III clinical studies have been promising. However, worldwide real safety data has reported life-threatening side effects due to the development of secondary autoimmune diseases (autoimmune hepatitis, encephalitis, or Drug Reaction with Eosinophilia Systemic Symptoms (DRESS) syndrome), which led to its withdrawal in 2018 [44].

Several moAbs studied for use in the treatment of MS have already been withdrawn for a variety of reasons. Atacicept increased relapse rates, muromonab showed unacceptable toxic effects, and tabalumab and ustekinumab did not show efficacy [11].

\section{Future directions}

Several moAbs are currently in clinical trials.

Ofatumumab is a completely human, anti-CD20 moAb. B cell depletion is less profound, with faster repletion compared to other moAbs. It was approved initially for intravenous treatment of chronic lymphocytic leukemia. The MIRROR phase II study with monthly subcutaneous administration of 100,300 , and $700 \mathrm{mg}$ was followed by the ASCLEPIOS studies I and II. These phase III studies compared ofatumumab with teriflunomide in relapsing multiple sclerosis. Annualised relapse rate reductions were $50.5 \%$ and $58.8 \%$ for teriflunomide and ofatumumab, respectively. Their approval is expected later this year, given the good results obtained in these studies $[45,46]$.

Ublituximab (UTX) is another anti-CD 20 antigen drug which has been developed for RMS patients. It has a higher potency and is expected to be administered intravenously, in smaller doses and at shorter intervals. The phase II randomised study (UTX vs. placebo) revealed no MRI activity, and additionally, no evidence of disease activity was observed in $74 \%$ of cases after 48 weeks of the survey.

ULTIMATE I, II and III phases studies, which have compared UTX to teriflunomide for efficacy and safety, with over 1,000 patients, have shown good results, and conclusions are expected in 2020 [47, 48].

Opicinumab, a new moAb treatment acting against LINGO-1 protein, is a promising remyelination drug. LINGOI prevents the transformation of young cells into oligodendrocytes. By blocking this function, the growth of oligodendrocytes, which play an essential role in myelination, is allowed. Opicinumab was evaluated in SYNERGY phase II trials, by infusion administered every four weeks, compared to IFNB1a, but without disability improvement vs. placebo in RMS. AFFINITY, another phase II study, compares Opicinumab with other DMTs with a better design for RMS. The results 
will be announced in 2022. In the phase II SYNERGY study, no significant side effects were reported $[49,50]$.

Elezanumab is a fully-humanised moAb acting against $\mathrm{RGMa}$, modulating $\mathrm{T}$ cell responses, and promoting axonal regeneration with remyelination and neuroprotection.

The current phase I study compares intravenous multiple doses of elezanumab ( $150 \mathrm{mg}, 600 \mathrm{mg}$, and 1,800 mg) vs. placebo in order to determine its safety profile and tolerability in RMS. Further research is required into this new moAb.

In summary, we conclude that most clinical trials on moAbs in MS have been sponsored by pharmaceutical companies, and that the time period during which they were conducted was too short to assess the safety of the tested drugs. Drug repurposing is an efficient way to save money and time, and comes with safety profile data.

The superior efficiency of moAbs is counterbalanced by the uncertain safety profile and high costs. The risks of secondary autoimmunity are challenging (alemtuzumab and daclizumab) for long-term planning of immunotherapy. Furthermore, more convenient administration of these medications, strictly on a monthly basis or several times a year, is complicated by monitoring for several months/years since the last administration. Comprehensive documentation, correct evaluation of the benefit-risk ratio, and professional expertise are crucial. Newly available therapies should be used in carefully selected cases. It depends on the particularities of the disease, the patient, and the healthcare system. Moreover, the choice should be accepted by the patient after they have been fully informed. Ongoing and post-marketing studies will bring new data and useful recommendations for everyday practice.

\section{References}

1. Alonso A, Hernán MA. Temporal trends in the incidence of multiple sclerosis: a systematic review. Neurology. 2008; 71(2): 129-135, doi: 10.1212/01.wnl.0000316802.35974.34, indexed in Pubmed: 18606967.

2. Sirbu $\mathrm{CA}$, Plesa FC, Dragoi $\mathrm{CM}$, et al. History of interferon treatments in multiple sclerosis-60 years of progress. Vols Farmacia. 2017; 65(1): 14-18.

3. Kułakowska A, Drozdowski W. Does interferon beta therapy affect survival of multiple sclerosis patients? Neurol Neurochir Pol. 2014; 48(6): 436-441, doi: 10.1016/j.pjnns.2014.10.003, indexed in Pubmed: 25482255.

4. Kułakowska A, Bartosik-Psujek H, Hożejowski R, et al. Selected aspects of the epidemiology of multiple sclerosis in Poland - a multicentre pilot study. Neurol Neurochir Pol. 2010; 44(5): 443-452, doi: 10.1016/s0028-3843(14)60134-1, indexed in Pubmed: 21082490.

5. Río J, Tintoré M, Sastre-Garriga J, et al. Change in the clinical activity of multiple sclerosis after treatment switch for suboptimal response. Eur J Neurol. 2012; 19(6): 899-904, doi: 10.1111/j.1468-1331.2011.03648.x, indexed in Pubmed: 22289050.

6. Sirbu CA, Furdu-Lungut E, Plesa CF, et al. et al.. M. Pharmacological treatment of relapsing remitting multiple sclerosis-where we are throw evidence based medicine? -review Farmacia. 2016; 64(5): 651-6.
7. Arneth BM. Impact of B cells to the pathophysiology of multiple sclerosis. J Neuroinflammation. 2019; 16(1): 128, doi: 10.1186/s12974019-1517-1, indexed in Pubmed: 31238945.

8. Derada Troletti C, Fontijn RD, Gowing E, et al. Inflammation-induced endothelial to mesenchymal transition promotes brain endothelial cell dysfunction and occurs during multiple sclerosis pathophysiology. Cell Death Dis. 2019; 10(2): 45, doi: 10.1038/s41419-018-1294-2, indexed in Pubmed: 30718504.

9. Dendrou CA, Fugger L, Friese MA. Immunopathology of multiple sclerosis. Nat Rev Immunol. 2015; 15(9): 545-558, doi: 10.1038/nri3871, indexed in Pubmed: 26250739.

10. Høglund RA, Maghazachi AA. Multiple sclerosis and the role of immune cells. World J Exp Med. 2014; 4(3): 27-37, doi: 10.5493/wjem. v4.i3.27, indexed in Pubmed: 25254187.

11. Voge NV, Alvarez E. Monoclonal Antibodies in Multiple Sclerosis: Present and Future. Biomedicines. 2019; 7(1), doi: 10.3390/biomedicines7010020, indexed in Pubmed: 30875812.

12. Stüve 0 , Cepok S, Elias B, et al. Clinical stabilization and effective B-lymphocyte depletion in the cerebrospinal fluid and peripheral blood of a patient with fulminant relapsing-remitting multiple sclerosis. Arch Neurol. 2005; 62(10): 1620-1623, doi: 10.1001/ archneur.62.10.1620, indexed in Pubmed: 16216948.

13. Veldhuijzen van Zanten SEM, De Witt Hamer PC, van Dongen GA. Brain Access of Monoclonal Antibodies as Imaged and Quantified by Zr-Antibody PET: Perspectives for Treatment of Brain Diseases. J Nucl Med. 2019; 60(5): 615-616, doi: 10.2967/jnumed.118.220939, indexed in Pubmed: 30737301.

14. Preziosa P, Rocca MA, Filippi M. PET is necessary to make the next step forward in understanding MS pathophysiology - No. Mult Scler. 2019; 25(8): 1088-1090, doi: 10.1177/1352458518820238, indexed in Pubmed: 30810073.

15. Pieters T. Interferon: The Science and Selling of a Miracle Drug, 264 pp., illustrated. New York, Routledge, ISBN: 0-415-34246-5. 2005.

16. Tovey MG, Lallemand C. Immunogenicity and other problems associated with the use of biopharmaceuticals. Ther Adv Drug Saf. 2011; 2(3): 113-128, doi: $10.1177 / 2042098611406318$, indexed in Pubmed: 25083207.

17. Brown JW, Coles A, Horakova D, et al. MSBase Study Group. Association of Initial Disease-Modifying Therapy With Later Conversion to Secondary Progressive Multiple Sclerosis. JAMA. 2019; 321(2): 175-187, doi: 10.1001/jama.2018.20588, indexed in Pubmed: 30644981.

18. Harding $\mathrm{K}$, Williams $\mathrm{O}$, Willis $\mathrm{M}$, et al. Clinical Outcomes of Escalation vs Early Intensive Disease-Modifying Therapy in Patients With Multiple Sclerosis. JAMA Neurol. 2019; 76(5): 536-541, doi: 10.1001/jamaneurol.2018.4905, indexed in Pubmed: 30776055.

19. Steinman $L$. The discovery of natalizumab, a potent therapeutic for multiple sclerosis. J Cell Biol. 2012; 199(3): 413-416, doi: 10.1083/ jcb.201207175, indexed in Pubmed: 23109666.

20. Shirani A, Stüve 0. Natalizumab for Multiple Sclerosis: A Case in Point for the Impact of Translational Neuroimmunology. J Immunol. 2017; 198(4): 1381-1386, doi: 10.4049/jimmunol.1601358, indexed in Pubmed: 28167648.

21. Ali R, Nicholas RS, Muraro PA. Drugs in development for relapsing multiple sclerosis. Drugs. 2013; 73(7): 625-650, doi: 10.1007/s40265013-0030-6, indexed in Pubmed: 23609782.

22. Rice GPA, Hartung HP, Calabresi PA. Anti-alpha4 integrin therapy for multiple sclerosis: mechanisms and rationale. Neurology. 2005; 
64(8): 1336-1342, doi: 10.1212/01.WNL.0000158329.30470.D0, indexed in Pubmed: 15851719.

23. Radue EW, Stuart WH, Calabresi PA, et al. SENTINEL Investigators, SENTINEL Investigators. Natalizumab plus interferon beta-1a for relapsing multiple sclerosis. N Engl J Med. 2006; 354(9): 911-923, doi: 10.1056/NEJMoa044396, indexed in Pubmed: 16510745.

24. Pietropaolo V, Prezioso C, Bagnato F, et al. John Cunningham virus: an overview on biology and disease of the etiological agent of the progressive multifocal leukoencephalopathy. New Microbiol. 2018; 41(3): 179-186, indexed in Pubmed: 29620790.

25. Graf J, Aktas O, Rejdak K, et al. Monoclonal Antibodies for Multiple Sclerosis: An Update. BioDrugs. 2019; 33(1): 61-78, doi: 10.1007/ s40259-018-0327-9, indexed in Pubmed: 30604390.

26. Oshima Y, Tanimoto T, Yuji K, et al. Drug-associated progressive multifocal leukoencephalopathy in multiple sclerosis patients. Mult Scler. 2019; 25(8): 1141-1149, doi: 10.1177/1352458518786075, indexed in Pubmed: 29985084.

27. Kolcava J, Hulova M, Benesova Y, et al. The value of anti-JCV antibody index assessment in multiple sclerosis patients treated with natalizumab with respect to demographic, clinical and radiological findings. Mult Scler Relat Disord. 2019; 30: 187-191, doi: 10.1016/j. msard.2019.02.019, indexed in Pubmed: 30785075.

28. Major EO, Yousry TA, Clifford DB. Pathogenesis of progressive multifocal leukoencephalopathy and risks associated with treatments for multiple sclerosis: a decade of lessons learned. Lancet Neurol. 2018; 17(5): 467-480, doi: 10.1016/S1474-4422(18)30040-1, indexed in Pubmed: 29656742.

29. Kachuck NJ. Registries, research, and regrets: is the FDA's post-marketing REMS process not adequately protecting patients? Ther Adv Neurol Disord. 2011; 4(6): 339-347, doi: 10.1177/1756285611424461, indexed in Pubmed: 22164188.

30. Schwab N, Schneider-Hohendorf T, Melzer N, et al. Natalizumab-associated PML. Neurology. 2017; 88(12): 1197-1205, doi: 10.1212/ wnl.0000000000003739.

31. Fragoso YD, Adoni T, Brooks JB, et al. Practical Evidence-Based Recommendations for Patients with Multiple Sclerosis Who Want to Have Children. Neurol Ther. 2018; 7(2): 207-232, doi: 10.1007/s40120018-0110-3, indexed in Pubmed: 30167914.

32. Scalfari A, Muraro P. Monoclonal Antibody Therapy and Long-term Outcomes in Multiple Sclerosis - The Challenge of Treatment Optimisation. European Neurological Review. 2018; 13(2): 78, doi: 10.17925/enr.2018.13.2.78.

33. De Angelis F, John NA, Brownlee WJ. Disease-modifying therapies for multiple sclerosis. BMJ. 2018; 363: k4674, doi: 10.1136/bmj.k4674, indexed in Pubmed: 30482751.

34. Knier B, Hemmer B, Korn T. Novel monoclonal antibodies for therapy of multiple sclerosis. Expert Opin Biol Ther. 2014; 14(4): 503-513, doi: 10.1517/14712598.2014.887676, indexed in Pubmed: 24579720.

35. Rau D, Lang M, Harth A, et al. Listeria Meningitis Complicating Alemtuzumab Treatment in Multiple Sclerosis-Report of Two Cases. Int J Mol Sci. 2015; 16(7): 14669-14676, doi: 10.3390/ijms160714669, indexed in Pubmed: 26132570.

36. Kappos L, Li D, Calabresi P, et al. Long-term safety and efficacy of ocrelizumase II, randomised, multicentre trial. Lancet. 2011; 378(9805): 1779-87, doi: 10.1016/S0140-6736(11)61649-8.

37. Havrdová E, Arnold DL, Bar-Or A, et al. No evidence of disease activity (NEDA) analysis by epochs in patients with relapsing multi- ple sclerosis treated with ocrelizumab vs interferon beta-1a. Mult Scler J Exp Transl Clin. 2018; 4(1): 2055217318760642, doi: 10.1177/2055217318760642, indexed in Pubmed: 29568544.

38. ICER Institute for Clinical and Economic Review. Disease-modifying therapies for relapsing-remitting and primary-progressive multiple sclerosis: effectiveness and value. Final evidence report. https:// icer-review.org/wp-content/uploads/2016/08/CTAF_MS_Final_Report_030617.pdf. (2017).

39. Dobson R, Dassan P, Roberts M, et al. UK consensus on pregnancy in multiple sclerosis: 'Association of British Neurologists' guidelines. Pract Neurol. 2019; 19(2): 106-114, doi: 10.1136/practneurol-2018-002060, indexed in Pubmed: 30612100.

40. Sorensen PS, Sellebjerg F. Pulsed immune reconstitution therapy in multiple sclerosis. Ther Adv Neurol Disord. 2019; 12: 1756286419836913, doi: 10.1177/1756286419836913, indexed in Pubmed: 30944586.

41. Li H, Hu F, Zhang Y, et al. Comparative efficacy and acceptability of disease-modifying therapies in patients with relapsing-remitting multiple sclerosis: a systematic review and network meta-analysis. J Neurol. 2019 [Epub ahead of print], doi: 10.1007/s00415-019-09395-w, indexed in Pubmed: 31129710.

42. Cree BAc. Rituximab is an acceptable alternative to ocrelizumab for treating multiple sclerosis - Commentary. Mult Scler. 2018; 24(9): 1161-1162, doi: 10.1177/1352458518760717, indexed in Pubmed: 29468947.

43. Piehl F, Hillert J. Rituximab is an acceptable alternative to ocrelizumab for treating multiple sclerosis - Yes. Mult Scler. 2018; 24(9): 11571159, doi: 10.1177/1352458518757930, indexed in Pubmed: 29468952.

44. Cohan SL, Lucassen EB, Romba MC, et al. Daclizumab: Mechanisms of Action, Therapeutic Efficacy, Adverse Events and Its Uncovering the Potential Role of Innate Immune System Recruitment as a Treatment Strategy for Relapsing Multiple Sclerosis. Biomedicines. 2019; 7(1), doi: 10.3390/biomedicines7010018, indexed in Pubmed: 30862055.

45. Bar-Or A, Grove RA, Austin DJ, et al. Subcutaneous ofatumumab in patients with relapsing-remitting multiple sclerosis: The MIRROR study. Neurology. 2018; 90(20): e1805-e1814, doi: 10.1212/ WNL.0000000000005516, indexed in Pubmed: 29695594.

46. Hauser S. Efficacy and safety of ofatumumab versus teriflunomide in relapsing multiple sclerosis: results of the phase 3 ASCLEPIOS I and II trials. Oral presentation. : ECTRIMS.

47. Long-term follow-up results from the phase 2 multicenter study of ublituximab (UTX), a novel glycoengineered anti-CD20 monoclonal antibody (mAb), in patients with relapsing multiple sclerosis (RMS), ECTRIMS Online Library. Fox E Sep. ; 12: 2019.

48. Steinman L, et al. Study design and patient demographics of the ULTIMATE phase III trials evaluating Ublituximab (UTX), a novel glycoengineered anti-CD20 monoclonal antibody (mAb), in patients with relapsing multiple sclerosis (RMS). ECTRIMS Online Library.

49. Cadavid Efficacy Analysis of the Anti-LINGO-1 Monoclonal Antibody BIIB033 in Acute Optic Neuritis: The RENEW Trial. AAN 2015: P7. ; 202.

50. Cadavid D, Mellion M, Hupperts R, et al. SYNERGY study investigators. Safety and efficacy of opicinumab in patients with relapsing multiple sclerosis (SYNERGY): a randomised, placebo-controlled, phase 2 trial. Lancet Neurol. 2019; 18(9): 845-856, doi: 10.1016/S14744422(19)30137-1, indexed in Pubmed: 31285147. 